\title{
The R\&D of a Novel Sulfur Tolerant CO Shift Catalyst and Its Application in the Integrated Low Water Gas Ratio Process
}

\author{
Bonan Liu', Jiefei Xiao², Tiancun Xiao ${ }^{3}$, Qiuyun Zong2 ${ }^{2 *}$ \\ ${ }^{1}$ State Key Laboratory of Heavy Oil Processing, China University of Petroleum (Beijing), Beijing, China \\ ${ }^{2}$ Qingdao LianXin Catalytic Materials Co. Ltd., Qingdao, China \\ ${ }^{3}$ Inorganic Chemistry Laboratory, University of Oxford, Oxford, UK \\ Email: *zqy1959@163.com
}

How to cite this paper: Liu, B.N., Xiao, J.F., Xiao, T.C. and Zong, Q.Y. (2017) The R\&D of a Novel Sulfur Tolerant CO Shift Catalyst and Its Application in the Integrated Low Water Gas Ratio Process. Advances in Materials Physics and Chemistry, 7, 113-122.

https://doi.org/10.4236/ampc.2017.74010

Received: March 6, 2017

Accepted: April 16, 2017

Published: April 20, 2017

Copyright $\odot 2017$ by authors and Scientific Research Publishing Inc. This work is licensed under the Creative Commons Attribution International License (CC BY 4.0).

http://creativecommons.org/licenses/by/4.0/

\begin{abstract}
The QDB-5 sulfur tolerant CO shift catalyst, with anti-methanation property by supported compositing alkali promoters, has been proved to effectively reduce the outlet methane content in the condition of a low water gas ratio. Thus, a new technology based on a lower water/gas ratio than before has been developed with the new catalyst. The $\mathrm{CO}$ conversion at lower temperatures and catalyst stability were confirmed by long term industrial application. The high temperature catalyst performance also showed a better result than the conventional commercial catalyst, with higher $\mathrm{CO}$ conversion and well controlled methane outlet. Our research and the industrial application of catalyst have shown the importance of alkali metals as core promoters for such kind of catalysts.
\end{abstract}

\section{Keywords}

Shell Coal Gasification Process, Low Water Gas Ratio, Methanation, Alkali Metal Promoters, Industrial Application

\section{Introduction}

Along with the recent developments of coal chemistry in China, new types of coal gasification technology have been continuously introduced into the Chinese market. The Shell Coal Gasification (SCG) developed by Shell Co. Ltd, modified Lurgi pulverized coal gasification $(B G L)$ as well as the Chinese own branded $H T-L$ pulverized coal gasification technology have attracted increasing public attentions with much success in the industry [1] [2]. However, there are still more than $60 \mathrm{~mol} \%$ of $\mathrm{CO}$ content in the gasification-generated crude 
syngas (mainly contains $\mathrm{CO}+\mathrm{H}_{2}$ ) which has greatly limited the application of downstream productions such as methanol and ammonium synthesis. Normally, a water-gas-shift catalytic process, in which the $\mathrm{CO}$ content can be catalytically converted with the system added water steam, is employed to further adjust the $\mathrm{CO} / \mathrm{H}_{2}$ of syngas before the downstream productions. Here the chemistry involved is based on the reaction of $\mathrm{CO}+\mathrm{H}_{2} \mathrm{O}=\mathrm{CO}_{2}+\mathrm{H}_{2}$ (in this reaction water leads to the shift of the $\mathrm{CO}$ on the left hand, resulting in $\mathrm{H}_{2}$ on the other side), and when there are sulfur contents in the crude syngas (e.g. $\mathrm{H}_{2} \mathrm{~S}$ in ppms), sulfur tolerant water-gas-shift catalyst (i.e. $\mathrm{MgAlO}_{4}$ spinel modified CoMo supported $\gamma-\mathrm{Al}_{2} \mathrm{O}_{3}$ ) is routinely used in such reaction. The high $\mathrm{CO}$ concentration (i.e. $60 \mathrm{~mol} \%$ or higher) inevitably increases the steam (water) usage, while it also frequently results in the methanation side reaction $\left(\mathrm{CO}+3 \mathrm{H}_{2}=\mathrm{CH}_{4}+\mathrm{H}_{2} \mathrm{O}\right)$ from which the yield of methane could be sparked leading to a sharp increase in catalyst bed temperature (this phenomenon is exothermic, which has been described as "catalyst bed temperature flying" in the industry) [3] [4] [5] [6].

Our institution, along with Qingdao Lianxin Co. Ltd have been focusing on the study of methanation mechanism in a water-gas-shift process for many years with great knowledges built on long-term industrial experiences. The Chinese own branded QDB-4 catalyst and the newly developed QDB-5 which have been soon applied in the industry, combined with the optimized "low water gas ratio" technology (such process requires only a less than 1 water/dry gas ratio, which is much lower than the traditional figure of 2 or higher), have been proved to have overcome the current methanation problem of water-gas-shift system with effectively reduced water usage and a particularly desired better control on the catalyst bed temperature. On the other hand, the process energy cost in the production has been effectively cut to a minimum, and it has been confirmed that integrated package consisting of QDB catalysts and process design would be beneficial to those coal producing regions in the western China with poor water resources, for them to develop a healthy and sustainable coal chemistry [7] [8] [9]. The success of QDB catalysts and packed low water gas ratio technology are built on the innovations in an improved water molecule affinity achieved by the QDB catalysts, by which the catalytic centers better adsorb water in the reaction and enable a more efficient conversion of $\mathrm{CO}$, therefore the water usage is reduced with limited chances for methanation to happen (here CO is converted with water in a priority rather than going into the methanation pathway).

\section{Laboratory Investigation}

\subsection{Sample Preparation}

QDB-5 catalyst containing potassium promoters, in terms of Co-Mo-K/MgAl${ }_{2} \mathrm{O}_{4}$ $+\mathrm{Al}_{2} \mathrm{O}_{3}$ were prepared by 3 steps. The initial step is the co-sedimentation of magnesium aluminate spinel (25 wt\%, Sigma, reagent standard) with $\gamma-\mathrm{Al}_{2} \mathrm{O}_{3}$ (75 wt\%, Sigma, reagent standard), followed by extruding into columns (H: 5 $\mathrm{mm}, \mathrm{D}: 3 \mathrm{~mm}$ ) and dehydrated at $273 \mathrm{~K}$ for 24 hours, leading to the preparation of catalyst support. Secondly, Co and Mo promoters were introduced by im- 
pregnation of support with aqueous solution of cobalt and molybdate nitrate precursors (Sigma, reagent standard); after the previous 2 steps, the $\mathrm{K}$ cations in terms of $\mathrm{K}_{2} \mathrm{CO}_{3}$ were loaded by the catalyst via second impregnation. The referencing QDB-4 sample was made in the same way without adding $\mathrm{K}$ contents. Another group of $\mathrm{Co}-\mathrm{Mo} / \mathrm{MgO}-\mathrm{Al}_{2} \mathrm{O}_{3}$ samples were prepared via similar methods as above (all metal cations were introduced by nitrate salts), in absence of $\mathrm{K}$ precursors, representing the old generation commercial sulfur tolerant $\mathrm{CO}$ shift catalyst, named as cat. $\mathrm{K}$.

The active catalytic cations of prepared catalysts vary in types and amounts (for QDB-4 and QDB-5, $2 \mathrm{wt} \% \mathrm{CoO}, 8 \mathrm{wt} \% \mathrm{MoO}_{3}$, and QDB-5 particularly has extra $5 \mathrm{wt} \% \mathrm{~K}_{2} \mathrm{O}$; for commercial cat. $\mathrm{K}$, there are $3.5 \mathrm{wt} \% \mathrm{CoO}$ and $8 \mathrm{wt} \%$ $\mathrm{MoO}_{3}$ ).

All catalyst preparations start with a process of "sedimentation forming support", followed by one or two impregnations to load the metal cations that are potentially used as the catalytic centers in the water-gas-shift reaction (CO conversion with water). Here the introduction of $\mathrm{K}$ cations to the QDB-5 catalyst employs a second impregnation step, which better reserves $\mathrm{K}$ catalytic centers on the catalyst surface. Such second impregnation has only limited influence on the first-impregnated Mo and Co cations, based on the fact that $\mathrm{K}$ cations with a smaller diameter can fill into the spaces between the larger cations (Mo \& Co) while do not possess a disturbance on their distributions.

\section{Experimental}

In this research the QDB catalysts are tested in the laboratory experiments before a further report and discussion on their industrial performances.

The catalyst test employed a fixed bed system as shown in the Figure 1, simulating the real conditions $(3.7 \mathrm{Mpa}, 700 \mathrm{~K})$ in the first $\mathrm{CO}$ conversion reactor

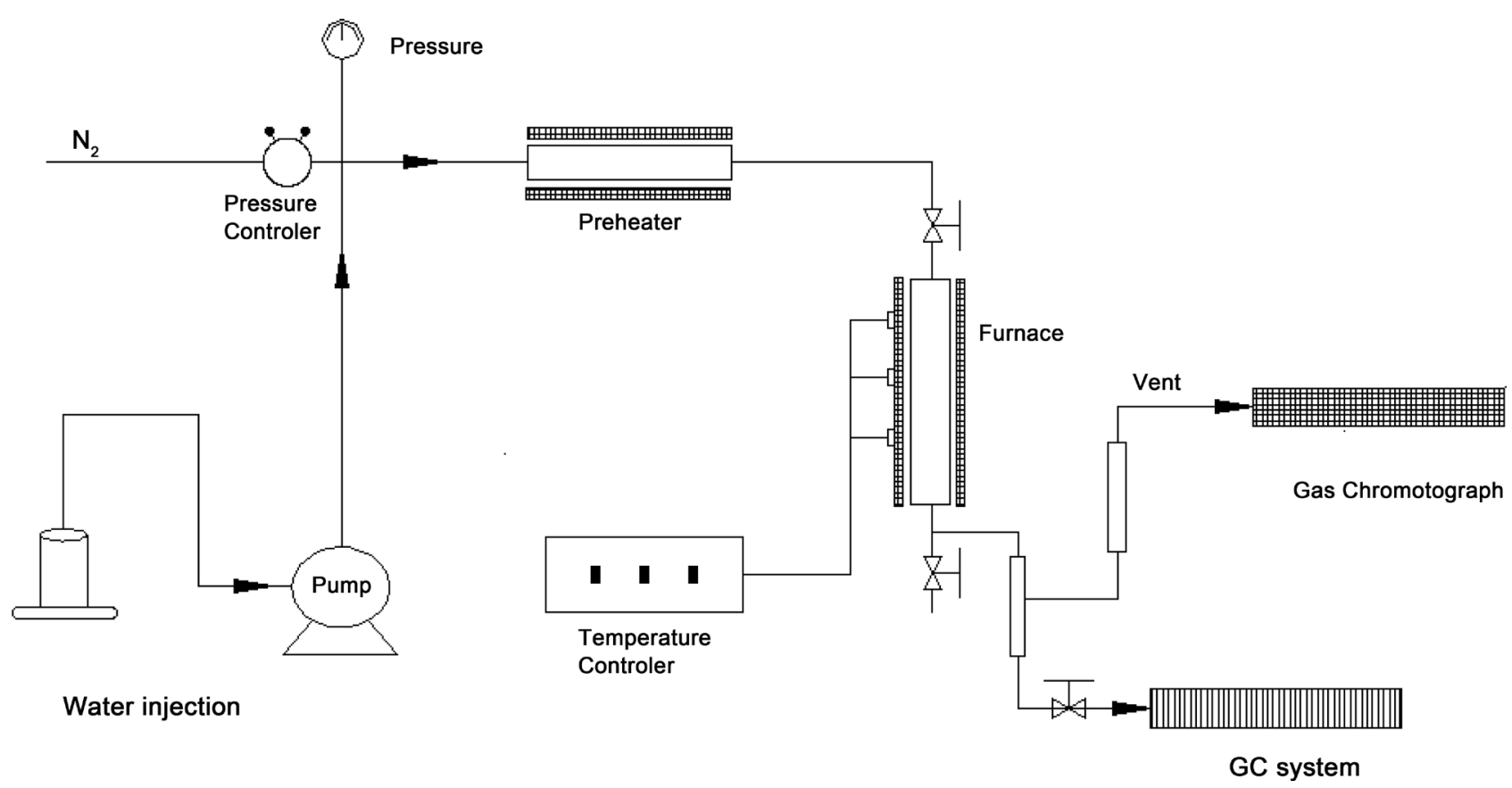

Figure 1. WGSR system employed in the catalyst performance test. 
after Shell gasifier. Each time, 10 grams of shaped catalysts were tested under a gaseous hourly space velocity (GHSV) of $3000 \mathrm{~h}^{-1}$. The gas feed stock composition is customized close to the industrial outlet of a Shell gasifier (dry feed coal derived syngas composition of $\mathrm{CO} 65 \mathrm{~mol} \%, \mathrm{CO}_{2} 8 \mathrm{~mol} \%, \mathrm{H}_{2} 20 \mathrm{~mol} \%$ and $\mathrm{N}_{2}$ for complement, inlet $\mathrm{H}_{2} \mathrm{~S}$ concentration $3000 \mathrm{ppm}$ ). Water is injected into the system by a HPLC pump, passing through a preheater working at $423 \mathrm{~K}$ to get the water vaporized in a calibrated rate. The gas outlet is directly transported into online GC system for detection (Agilent 7890, with TCD, FID and FPD).

Before the reaction, the gas line is switched to a parallel gas line $\left(3 \mathrm{~mol} \% \mathrm{H}_{2} \mathrm{~S}\right.$, $47 \mathrm{~mol} \% \mathrm{H}_{2}$ and $50 \mathrm{~mol} \% \mathrm{~N}_{2}$ ), and the catalyst is pre-sulfurized at $523 \mathrm{~K}$ for $3 \mathrm{~h}$, until the gas outlet sulfur composition is stable.

\subsection{Results and Discussion}

Tables 1-3 exhibit the achieved results by different samples at various conditions in accord with the industrial requirements. Working at a high water gas ratio (1 or higher), all the catalysts guaranteed an effective CO conversion from upper $65 \mathrm{~mol} \%$ in the inlet feedstock to $21 \mathrm{~mol} \%$ or lower in the outlet effluent.

Table 1. W/G vs. out $\mathrm{CH}_{4}$ mol\% for cat. K., with an error bar of " 0.01 ".

\begin{tabular}{|c|c|c|c|c|c|c|c|}
\hline \multirow{2}{*}{$\mathrm{W} / \mathrm{G}$} & \multirow{2}{*}{ Pres $\mathrm{MPa}$} & \multirow{2}{*}{$\mathrm{GHSV} \mathrm{h}^{-1}$} & \multicolumn{2}{|c|}{ Temp./K } & \multicolumn{3}{|c|}{ Gas composition, mol\% } \\
\hline & & & inlet & Cat. bed & Inlet CO & Out CO & Out $\mathrm{CH}_{4}$ \\
\hline 0.25 & 3.70 & 3000 & 523 & 700 & 65.10 & 46.50 & 2.01 \\
\hline 0.50 & 3.70 & 3000 & 523 & 700 & 64.90 & 34.10 & 1.09 \\
\hline 0.80 & 3.70 & 3000 & 523 & 700 & 64.60 & 27.20 & 0.48 \\
\hline 1.00 & 3.70 & 3000 & 523 & 700 & 65.30 & 21.30 & 0.06 \\
\hline
\end{tabular}

Table 2. W/G vs. out $\mathrm{CH}_{4}$ mol\% for QDB-4, with an error bar of " 0.01 ".

\begin{tabular}{|c|c|c|c|c|c|c|c|}
\hline \multirow{2}{*}{ W/G } & \multirow{2}{*}{ Pres $\mathrm{MPa}$} & \multirow{2}{*}{$\mathrm{GHSV} \mathrm{h}^{-1}$} & \multicolumn{2}{|c|}{ Temp./K } & \multicolumn{3}{|c|}{ Gas composition, mol\% } \\
\hline & & & inlet & Cat. bed & Inlet CO & Out CO & Out $\mathrm{CH}_{4}$ \\
\hline 0.25 & 3.70 & 3000 & 523 & 700 & 64.80 & 43.00 & 0.99 \\
\hline 0.50 & 3.70 & 3000 & 523 & 700 & 64.90 & 29.80 & 0.75 \\
\hline 0.80 & 3.70 & 3000 & 523 & 700 & 65.10 & 20.90 & 0.34 \\
\hline 1.00 & 3.70 & 3000 & 523 & 700 & 64.90 & 19.10 & 0.05 \\
\hline
\end{tabular}

Table 3. W/G vs. out $\mathrm{CH}_{4}$ mol\% for QDB-5 with $\mathrm{K}$ promoters, with an error bar of “0.01".

\begin{tabular}{|c|c|c|c|c|c|c|c|}
\hline \multirow{2}{*}{$\mathrm{W} / \mathrm{G}$} & \multirow{2}{*}{ Pres $\mathrm{MPa}$} & \multirow{2}{*}{$\mathrm{GHSV} \mathrm{h}^{-1}$} & \multicolumn{2}{|c|}{ Temp./K } & \multicolumn{3}{|c|}{ Gas composition, mol\% } \\
\hline & & & inlet & Cat. bed & Inlet CO & Out CO & Out $\mathrm{CH}_{4}$ \\
\hline 0.25 & 3.70 & 3000 & 523 & 700 & 65.00 & 41.50 & 0.41 \\
\hline 0.50 & 3.70 & 3000 & 523 & 700 & 64.90 & 27.20 & 0.22 \\
\hline 0.80 & 3.70 & 3000 & 523 & 700 & 63.90 & 19.50 & 0.14 \\
\hline 1.00 & 3.70 & 3000 & 523 & 700 & 64.70 & 18.20 & 0.05 \\
\hline
\end{tabular}


The methane concentration in out gas was between 5 - 6 mol\% for all the samples, showing that high water gas ratio would significantly prohibit the methanation side reaction. However, at a lower water gas ratio (0.8) the methane concentration in outlet gas obviously increased on those $\mathrm{K}$ free samples (cat. K 0.48 and QDB-4 0.34). In the condition of the lowest water gas ratio (0.25), the methane concentration in out gas reached to the highest level for the $\mathrm{K}$ free samples, and especially, the traditional industry catalyst sample possessed a 2.01 mol\% methane concentration in the gas effluent. As a strong contrast, the $\mathrm{K}$ containing sample QDB-5 properly controlled the outlet methane concentration (0.41) at such a low water gas ratio. In accord with the excellent methane concentration control ability, the QDB-5 sample also exhibited the best CO conversion in the low water gas ratio conditions.

One notes that the efficacy of QDB-5 relies on the introduction of K cations, which dramatically improves the affinity of water molecule, thus, such better capture of reactant water, has forced the $\mathrm{CO}$ conversion to go into a way of $\mathrm{CO}_{2}$ generation, rather than the formation of methane. This has been confidentially supported by the above laboratory results, which show much higher $\mathrm{CH}_{4}$ yields in the reaction gas effluent over the commercial catalyst K. than the QDB-5 catalyst. Due to the limitation of lab-working hours, it is hard to perform a long-term (e.g. up to hundreds of hours as in the industry) test; however, the current results have clearly show the discrepant catalytic behaviors of different samples, highlighting the advantages of QDB-5 with anti-methanation. The long duration behaviors of catalysts are examined in the industry.

\section{Industrial Catalyst Characterization and Discussion}

We have employed FT-IR (Figure 2) to compare the QDB-5 (K containing) and QDB-4 (K free) samples before and after industrial long term running by focusing on the evolution of the Al-O structures. Obviously, potassium has been found to be successfully loaded by the QDB-5 catalyst (two bands at around $1380 \mathrm{~cm}^{-1}$ and $1520 \mathrm{~cm}^{-1}$, respectively) as a result of the alumina body binding with the 'fairly stable bicarbonate species coordinated to the $\mathrm{K}^{+}$, which could be attributed to the decomposition of the $\mathrm{CO}_{3}^{2-}$ ions in the precursor. The characteristic band for $\gamma-\mathrm{Al}_{2} \mathrm{O}_{3}$ has been maintained on the fresh QDB-5 sample indicating that loading potassium would not lead to significant damage to the support and hence the long term stability of the catalyst performance. After 2 years industrial serving, there is observed loss on the Al-O structure of the catalyst for both $\mathrm{K}$ containing catalyst (QDB-5) and $\mathrm{K}$ free catalyst (QDB-4). Part of the $\mathrm{K}$ species was lost on the 2 years QDB-5 catalyst, leading to the disappearance of the peak at around $1530 \mathrm{~cm}^{-1}$ and the erosion of the peak at about 1380 $1390 \mathrm{~cm}^{-1}$. The newly formed bicarbonate species coordinated to the $\mathrm{K}$ cations on the QDB-5 catalyst might be related to the anti-methanation property of the catalyst. The formed carbon species somehow inhibited the formation of $\mathrm{C}-\mathrm{H}$ bond on the catalyst surface thus reduced the chance of methanation.

Here the Raman spectra (Figure 3) help to complete the above explanations 


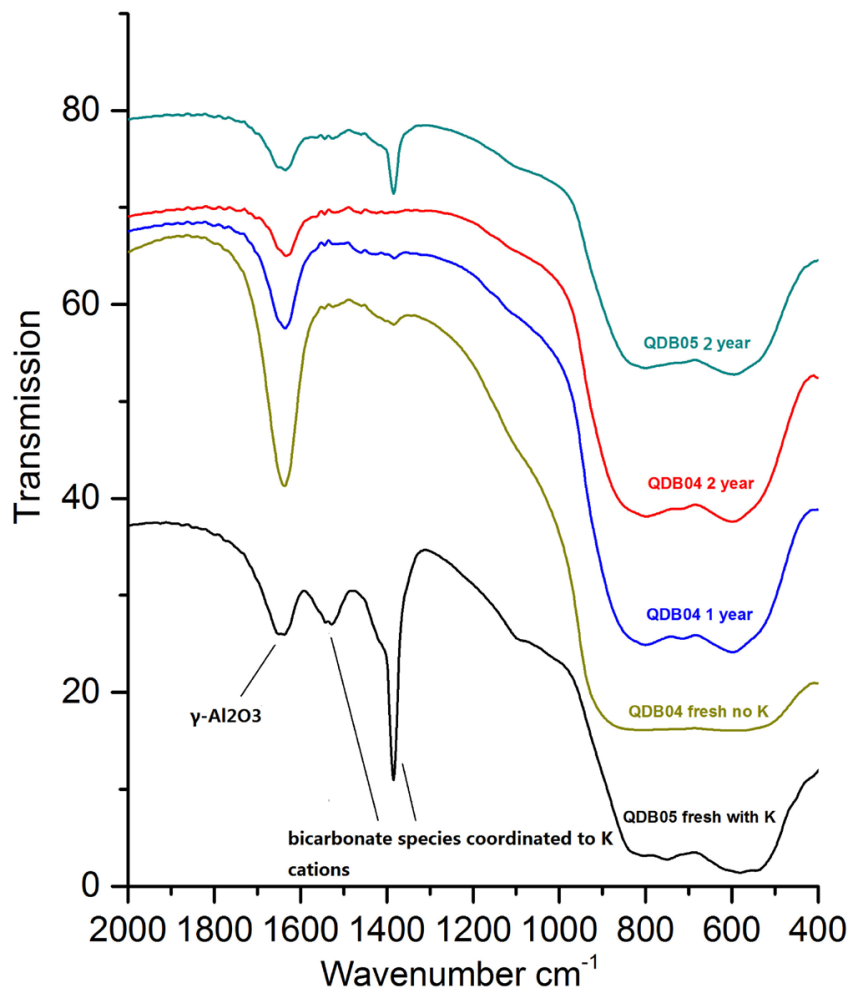

Figure 2. FT-IR spectra of fresh QDB-5 (with K), fresh QDB-4 (K free), post run QDB-4 (1 - 2 years) and post run QDB-5 (2 years).

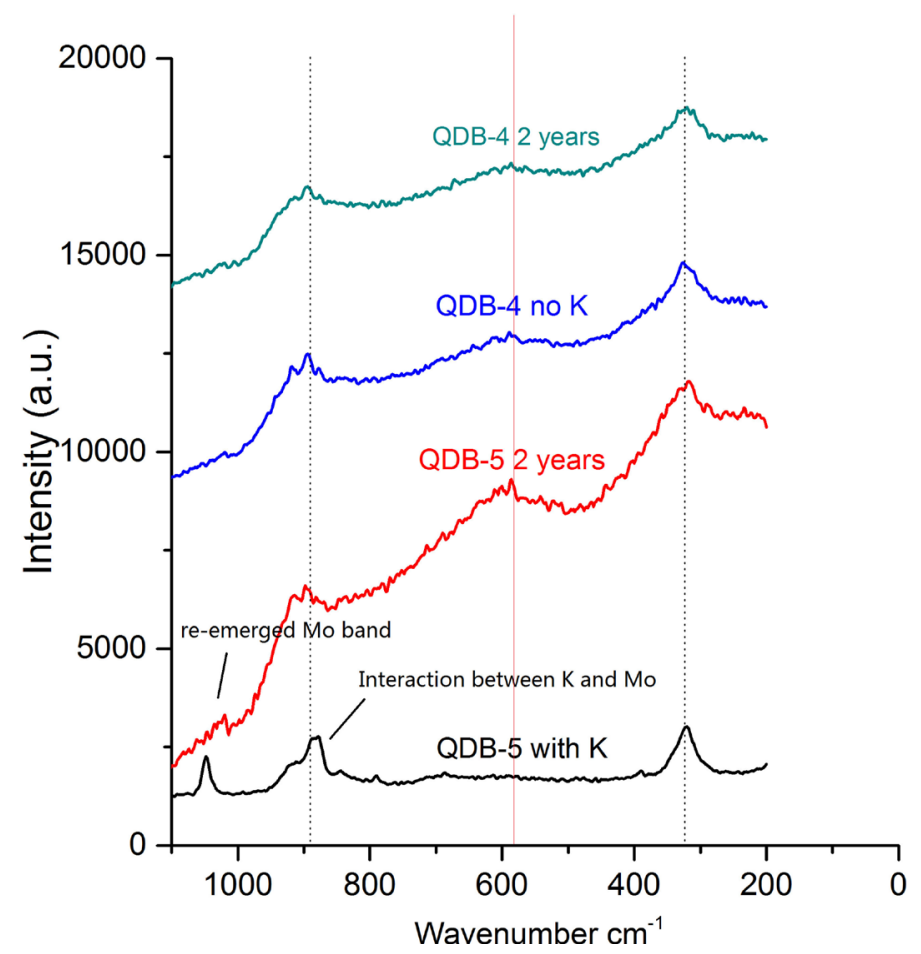

Figure 3. Raman spectra of the fresh QDB-5 catalyst (with K) and QDB-5 2 years served; fresh QDB-4 Kcatalyst (K free) and QDB-4 2 years served.

by better showing the interactions between $\mathrm{K}$ and Mo cations. In Figure 3, Raman bands at $1020 \mathrm{~cm}^{-1}, 900 \mathrm{~cm}^{-1}, 580 \mathrm{~cm}^{-1}$ and $320 \mathrm{~cm}^{-1}$ are corresponding to 
the Mo-O structures. Another two bands at $890 \mathrm{~cm}^{-1}$ and $1050 \mathrm{~cm}^{-1}$, only observed on QDB-5 samples, are related to the interactions between loaded $\mathrm{K}$ species and Mo species. Notably, the $1050 \mathrm{~cm}^{-1}$ band has partially covered the Mo-O band at $1020 \mathrm{~cm}^{-1}$, while the $890 \mathrm{~cm}^{-1}$ band seems also lead to a shift of the Mo-O band at $900 \mathrm{~cm}^{-1}$. After 2 years serving in the plants, the QDB- 5 catalyst has shown much stronger Mo-O bands (especially the band at $580 \mathrm{~cm}^{-1}$ ) when compared with the fresh catalyst QDB-4 (no K), indicating better stability of the catalytic properties. Interestingly, the overlapping between Mo-O bands and Mo-K bands disappeared $\left(890 \mathrm{~cm}^{-1}\right)$, or partially reduced $1050 \mathrm{~cm}^{-1}$. A possible explanation could be the interaction between $\mathrm{K}$ and Mo species have prevented the loss of the Mo-O structures during the long term reaction; the initially covered Mo-O structures gradually emerged as the Mo-K structure lost in the long term reaction. Another hypothesis would be the K-Mo-OxO species is no longer an everlasting structure in the long term run but an intermediate that can be converted back to Mo-O species with the loss of potassium.

\section{The Industrial Application in Low Water Gas Ratio Conditions}

The first industrial application of QDB-5 catalyst as well as the newly designed low water gas ratio technology launched in Liuzhou, Guangxi Province, China, 2007. The designed CO shift project supplied syngas for ammonia production of 300,000 ton/year. The first reactor outlet methane content was reduced to zero (the feedstock also had a $0.2 \%$ methane concentration further increased the technical difficulty) after the QDB-5 catalyst was applied. The methanation side reaction was absolutely inhibited while an effective $\mathrm{CO}$ conversion had been achieved (data shown in Table 4).

The first application of QDB-5 and low W/G technology for syngas supplement to methanol synthesis was initiated by Kaixiang Chemical Co., ltd, Henan Province, China, in 2008 . The $\mathrm{CO}$ conversion proceeded at $450^{\circ} \mathrm{C}$ with water gas ratio of $0.27-0.29$ (data shown in Table 5).

In 2009, the QDB-5 catalyst was applied to instead of the commercial K catalyst for syngas production in the Ammonium synthesis project by SINOPEC, in Hunan Province, China (data shown in Table 6). Due to special operating situation, the feedstock inlet temperature rose up to $560^{\circ} \mathrm{C}$ above. The QDB-5 catalyst exhibited marvelous high temperature stability and effectively inhibited the methanation effect.

Table 4. $\mathrm{CO}$ and $\mathrm{CH}_{4}$ concentration in the first reactor at Guangxi Liuzhou, 2007; with an error bar of " 0.01 ".

\begin{tabular}{ccccccc}
\hline \multirow{2}{*}{$\begin{array}{c}\text { Flow } \\
\mathrm{Nm}^{3} / \mathrm{h}\end{array}$} & Hot point ${ }^{\circ} \mathrm{C}$ & \multirow{2}{*}{$\mathrm{W} / \mathrm{G}$} & \multicolumn{4}{c}{ First reactor gas composition \% } \\
\cline { 5 - 7 } & & & Inlet CO & Outlet CO & Inlet $\mathrm{CH}_{4}$ & Outlet $\mathrm{CH}_{4}$ \\
\hline 71,200 & 401 & 0.24 & 66.8 & 45.6 & 0.00 & 0.00 \\
80,386 & 389.0 & 0.23 & 58.3 & 41.5 & 0.18 & 0.00 \\
97,310 & 390.1 & 0.26 & 59.3 & 40.5 & 0.16 & 0.14 \\
\hline
\end{tabular}


Table 5. $\mathrm{CO}$ and $\mathrm{CH}_{4}$ contentration in the first reactor at Kaixiang, Henan, 2008; with an error bar of " 0.01 ".

\begin{tabular}{|c|c|c|c|c|c|c|}
\hline \multicolumn{2}{|c|}{ Temp, ${ }^{\circ} \mathrm{C}$} & \multirow{2}{*}{ W/G } & \multicolumn{4}{|c|}{ First reactor gas composition $\%$} \\
\hline Inlet & Hot point & & Inlet CO & Outlet CO & Inlet $\mathrm{CH}_{4}$ & Outlet $\mathrm{CH}_{4}$ \\
\hline 231.0 & 448.9 & 0.28 & 64.71 & 35.01 & 0.02 & 0.016 \\
\hline 239.6 & 451.1 & 0.29 & 64.09 & 33.20 & 0.03 & 0.026 \\
\hline 243.1 & 446.7 & 0.27 & 64.93 & 36.10 & 0.00 & 0.00 \\
\hline
\end{tabular}

Table 6. Temperature recovery process after un-expected temperature drop emergency via QDB-5; with an error bar of “0.1". Hunan, SINOPEC, 2009.

\begin{tabular}{cccccc}
\hline & \multicolumn{5}{c}{ Catalyst bed temperature ${ }^{\circ} \mathrm{C}$} \\
\cline { 2 - 5 } TOS & Inlet & \multicolumn{3}{c}{ Catalyst bed section } & \\
\cline { 3 - 5 } & & Up & Mid & Down & \\
\hline 2008.12.24/10:00 & 195 & 170 & 200 & 210 & 248 \\
2008.12.24/10:40 & 197 & 172 & 206 & 229 & 262 \\
$2008.12 .24 / 10: 50$ & 200 & 174 & 208 & 234 & 271 \\
$2008.12 .24 / 11: 20$ & 207 & 178 & 224 & 286 & 286 \\
$2008.12 .24 / 11: 45$ & 227 & 184 & 230 & 323 & 208 \\
$2008.12 .24 / 11: 55$ & 237 & 190 & 240 & 366 & 350 \\
$2008.12 .24 / 12: 20$ & 249 & 216 & 359 & 448 & 388 \\
$2008.12 .24 / 13: 00$ & 248 & 233 & 381 & 456 & 458 \\
$2008.12 .24 / 13: 10$ & 247 & 239 & 384 & 456 & 447 \\
\hline
\end{tabular}

By the end of 2013, over 40 CO shift plants for Coal gasification in China have been modified to apply low water gas shift technology, accompanied by the designed QDB-5 catalyst with anti-methanation function.

The industrial performance proved that the activation temperature for QDB-5 catalyst was $170^{\circ} \mathrm{C}$ with guaranteed $\mathrm{CO}$ conversion. When the applied WHSV set to $4000-5000 \mathrm{~h}^{-1}$ (heavy duty, harsh condition), the catalyst still get activated as long as the inlet temperature reach $190^{\circ} \mathrm{C}$. The low temperature activity of QDB-5 no doubt made it special with the traditional CO shift catalyst.

The low temperature activity of QDB-5 is also proved to reduce the times for unexpected production shutdown. The diagram 6 showed the temperature changes after un-expected temperature drop (immediate temperature fall, caused by emergency issues) in a QDB-5 applied plant at Longyu Chem. Co. Ltd, in Puyang, China. By reducing the feedstock, the catalyst bed temperature was maintained and continuously increased to a normal level. All the data strongly proved the low temperature activity and stability of QDB-5 catalyst.

Table 7 showed the catalyst performance at $450^{\circ} \mathrm{C}$ after applied 2 years in first $\mathrm{CO}$ shift reactor. The catalyst still exhibited high $\mathrm{CO}$ conversion and the methane concentration was controlled to a near zero level in the outlet gas. The data was gained from a methanol plant by Linquan chem. Co., Ltd, in Anhui, China. 
Table 7. $\mathrm{CO}$ and $\mathrm{CH}_{4}$ contents in the first reactor at Linquan, Anhui, China, 2008

\begin{tabular}{|c|c|c|c|c|c|c|}
\hline \multicolumn{2}{|c|}{ Temp, ${ }^{\circ} \mathrm{C}$} & \multirow{2}{*}{$\begin{array}{l}\text { Flow } \\
\mathrm{M}^{3} / \mathrm{h}\end{array}$} & \multicolumn{4}{|c|}{ First reactor gas composition $\%$} \\
\hline Inlet & Hot point & & Inlet CO & Outlet CO & Inlet $\mathrm{CH}_{4}$ & Outlet $\mathrm{CH}_{4}$ \\
\hline 243.0 & 458.1 & 11,560 & 64.40 & 31.20 & 0.023 & 0.012 \\
\hline 251.6 & 453.7 & 11,630 & 63.56 & 30.72 & 0.021 & 0.020 \\
\hline 247.2 & 456.7 & 11,390 & 64.93 & 32.10 & 0.012 & 0.010 \\
\hline
\end{tabular}

\section{Summary}

The QDB-5 sulfur tolerant CO shift catalyst, which has been proved to have low temperature catalysis activity and anti-methanation property, showed many advantages than the traditional $\mathrm{CO}$ shift catalyst, in terms of higher $\mathrm{CO}$ conversion under severe conditions, low water usage and minimum outlet water production via low water gas ratio technology. The newly developed catalyst will further reduce the technical barrier for coal chemical industry and bring huge economic benefits for projects based on syngas production, including methanol synthesis, ammonium production and the coal to liquid (oil) programs.

By far the new generation water-gas-shift catalysts have figured out the problems caused by methanation side reactions, however, in practical applications, other issues do emerge. A critical problem that has been reported by one of the factories is the 'unavoidable' generation of organic sulfur contents which may occur as another side reaction in the sulfur tolerant catalyst promoted water-gas-shift reactions. One example is the formation of mercaptane, which will be a poison for the downstream sulfur recovery process. Based on our years know-how and experiences in such catalysts design, it is suggested that the next evolution of water-gas-shift catalyst would be sparked again on their sulfur-reduction effects.

\section{References}

[1] Minchener, A.J. (2005) Coal Gasification for Advanced Power Generation. Fuel, 84, 2222-2235.

[2] Martelli, E., Kreutz, T. and Consonni, S. (2009). Comparison of Coal IGCC with and without $\mathrm{CO}_{2}$ Capture and Storage: Shell Gasification with Standard vs. Partial Water Quench. Energy Procedia, 1, 607-614.

[3] Batista, M.S., Santiago, E.I., Assaf, E.M. and Ticianelli, E.A. (2005) Evaluation of the Water-Gas Shift and CO Methanation Processes for Purification of Reformate Gases and the Coupling to a PEM Fuel Cell System. Journal of Power Sources, 145, 50-54.

[4] Kim, S.H., Nam, S.-W., Lim, T.-H. and Lee, H.-I. (2008) Effect of Pretreatment on the Activity of Ni Catalyst for CO Removal Reaction by Water-Gas Shift and Methanation. Applied Catalysis B: Environmental, 81, 97-104.

[5] Yaccato, K., Carhart, R., Hagemeyer, A., Lesik, A., Strasser, P., Volpe, A.F., Turner, H., Weinberg, H., Grasselli, R.K. and Brooks, C. (2005) Competitive CO and $\mathrm{CO}_{2}$ Methanation over Supported Noble Metal Catalysts in High Throughput Scanning Mass Spectrometer. Applied Catalysis A: General, 296, 30-48.

[6] Li, J., Li, X., Liu, Y. and Zhang, J. (2017) Removal of Mercaptans from Light Oils 
Using Ionic Liquid-NaOH Aqueous Solution as Extractants. Chinese Journal of Chemical Engineering, 25, 171-174.

[7] Liu, B., Zong, Q., Du, X., Zhang, Z., Xiao, T. and AlMegren, H. (2015) Novel Sour Water Gas Shift Catalyst (SWGS) for Lean Steam to Gas Ratio Applications. Fuel Processing Technology, 134, 65-72.

[8] Liu, B., Zong, Q., Edwards, P.P., Zou, F., Du, X., Jiang, Z., Xiao, T. and AlMegren, H. (2012) Effect of Titania Addition on the Performance of $\mathrm{CoMo} / \mathrm{Al}_{2} \mathrm{O}_{3}$ Sour Water Gas Shift Catalysts under Lean Steam to Gas Ratio Conditions. Industrial \& Engineering Chemistry Research, 51, 11674-11680. https://doi.org/10.1021/ie3009764

[9] Zong, Q.Y., Liu, B.N., Zhou, C.L. and Chen, N.N. (2008) Performances and Application of Sulfur Tolerant QDB-04 Catalyst Promoted by Zr-Ce. Coal Chemical Industry, 135, 27-30.

Submit or recommend next manuscript to SCIRP and we will provide best service for you:

Accepting pre-submission inquiries through Email, Facebook, LinkedIn, Twitter, etc. A wide selection of journals (inclusive of 9 subjects, more than 200 journals)

Providing 24-hour high-quality service

User-friendly online submission system

Fair and swift peer-review system

Efficient typesetting and proofreading procedure

Display of the result of downloads and visits, as well as the number of cited articles

Maximum dissemination of your research work

Submit your manuscript at: http://papersubmission.scirp.org/

Or contact ampc@scirp.org 